\title{
COMBINED CORD DEGENERATION WITHOUT ANEMIA: A CASE REPORT WITH STUDIES BEARING ON THE "INTRINSIC FACTOR" OF CASTLE
}

\author{
By WALTER LINCOLN PALMER AND ROBERT T. PORTER \\ (From the Department of Medicine, University of Chicago, Chicago)
}

(Received for publication February 10, 1936)

The purpose of this paper is twofold: first, to report an unusual case of combined cord degeneration with achlorhydria but without anemia in which a prolonged spontaneous remission has been observed; and second, to describe some experimental observations bearing on the "intrinsic factor " of Castle. The case itself raises the question of the exact relationship of combined cord degeneration and pernicious anemia; the experimental studies raise the question of the exact rôle of the "intrinsic factor" of Castle in each of these conditions.

The prevailing view seems to be that in the absence of "ergotism, pellagra, syphilis, arteriosclerosis, and cachectic states" all patients with combined cord degeneration are in reality cases of pernicious anemia $(1,2,3,4,5,6)$. This is supported by the recognized frequency of combined cord degeneration in pernicious anemia, by the generally accepted opinion that the neurologic signs may precede the appearance of anemia by many months or years, and by the constancy of achlorhydria in both conditions.

It is universally agreed that in pernicious anemia degeneration of the spinal cord and brain frequently occur as a part of the disease process itself, but the incidence of such changes is estimated variously by different authors. Sturgis, Isaacs, Goldhamer, Bethell, and Farrar (7) in a recent review of the literature found estimates ranging from less than 25 per cent to 90 per cent or more, the majority of writers favoring a frequency of about 70 per cent.

In those cases in which an interval of time has occurred between the appearance of the neurologic manifestations and the anemia, the interval has been of variable duration. In Woltmann's series (4) the longest period was thirteen months; in Bramwell's case (8) it was three years; in Grinker's (9), four years, but in neither Bramwell's nor Grinker's reports are the descriptions of the blood findings quite adequate. There seem to be occasional cases of combined cord degeneration in which anemia does not develop over a period of years, if at all. Russell, Batten, and Collier (10) described the clinical course and autopsy findings in two such cases, one of four months' and the other of thirteen months' duration. In neither of these was anemia present. In the first case, the red blood cell count two days before death is given as $4,500,000$ cells per cubic millimeter, hemoglobin, 90 per cent; in the second, no figures are recorded, but the statement is made, "There was no anemia." Ungley and Suzman (6), in their study of combined cord degeneration, noted six cases in which no definite anemia was present. The three patients who survived for more than two years without liver treatment had comparatively high counts, viz., 5.6, 4.45, and 3.9 millions per cu. $\mathrm{mm}$. respectively. No further details are given with regard to these cases. Castle, Heath, and Strauss (11) refer to a similar case (Case C), but the symptoms were only of one month's duration. Allen (12) reported a case of combined cord degeneration without anemia, but it was only of ten months' duration. Vanderhoof (13) described six patients in whom the duration was longer, but the reports are incomplete. Wilkinson (14) states that he "has examined 39 cases of subacute combined degeneration without anemia," but further details are not given. Beebe and Wintrobe (15) describe a case of two years' duration, but the picture is somewhat obscured by the fact that liver therapy was given from time to time in spite of the fact that there was no anemia. Greenfield and O'Flynn (16) in reviewing forty-five cases of subacute combined cord degeneration, noted two cases in which the first red cell count was high, 5.5 million in one and 4.85 million in the other, but no further details are given. Sargent and Harris (17) mention having seen two cases of combined cord degeneration without anemia and report in detail one of two years' duration. In this case liver had not been given and yet the red blood count was 4.96 million, hemoglobin 88 per cent, color index 0.9 . Sanford (27) cites three cases of cord degeneration of indefinite duration with a normal blood picture. All of these are said to have improved after the administration of liver therapy. Briggs and Oerting (28) refer to a case with a normal blood picture, but the published abstract does not contain the full details. It apparently has not been completely settled, therefore, whether in the absence of "ergotism, pellagra, syphilis, arteriosclerosis and cachectic states" combined cord degeneration with achlorhydria but without anemia must be considered as pernicious anemia or whether it may be a disease sui generis.

There is apparently a complete unanimity of opinion with regard to the invariable association of achlorhydria with combined system disease regardless of the presence or absence of anemia. Wilkinson (14) states that he has "fully confirm (ed) the findings of other observers that achylia gastrica exists in 100 per cent of such cases." Greenfield and O'Flynn (16) found achlorhydria to be a constant feature in their series of forty- 
five cases. In this connection it is interesting to note that Sturgis, Isaacs, Goldhamer, Bethell, and Farrar (7), after weighing all the evidence, conclude that true pernicious anemia, irrespective of the cord changes, is invariably associated with true achylia gastrica. In a sense then, achylia gastrica may be considered as the constant link between the two conditions.

According to the concept of Castle (20) a macrocytic anemia should develop whenever there is an absence of "intrinsic factor" in the gastric secretion, unless there is an adequate intake of liver, liver extract, or other antianemic substances. On this basis Beebe and Wintrobe (15) suggested that the demonstration of the presence or absence in the gastric juice of the "intrinsic factor" of Castle might be employed as a diagnostic test for pernicious anemia. They were unable to demonstrate the presence of the "intrinsic factor" in two cases in which only a tentative diagnosis of pernicious anemia had been made and concluded therefrom that the "test" had substantiated the tentative diagnosis. Theoretically the principle involved here seems simple, but there are certain difficulties which have not yet been eliminated. Isaacs, Goldhamer and Sturgis (18) have demonstrated the presence of "intrinsic factor" in the gastric secretion in pernicious anemia by collecting and using quantities of juice comparable to that secreted by a normal stomach. They suggest that the deficiency of "intrinsic factor" is a relative rather than an absolute one. This observation is not incompatible with the work of Castle, but it raises the problem of the determination of the minimum amount of "intrinsic factor" compatible with a normal blood picture. Exact quantitative methods of measurement are not yet available, but it is quite probable that the maintenance amount will be found to vary in different individuals, particularly when such factors as diarrhea, malnutrition, and inadequate intake of food are present. Further difficulties arise from the work of Barnett (19), which is, in part, contradictory to that of Castle. Barnett found the "intrinsic factor" to be present in an apparent case of pernicious anemia, and on the other hand, failed to find it in simple achlorhydria without anemia. Hartfall and Witts (29) found the "intrinsic factor" present in variable amounts in simple achlorhydric anemia. In some cases the result was questionable, and Hartfall was forced to the verdict "that it is not proved that the gastric juice in simple achlorhydric anemia always contains the intrinsic factor of Castle in amounts comparable with normal."

Only four observations have been found in the literature with regard to the presence or absence of "intrinsic factor" in combined cord degeneration without anemia. Castle, Heath, and Strauss (11) reported a positive response with a reticulocytosis of 12.8 per cent on the tenth day. Beebe and Wintrobe (15) on the other hand failed to obtain a response. In the former case the symptoms were only of one month's duration; in the latter, the picture was complicated by intermittent liver therapy. Briggs and Oerting (28) reported obtaining a prompt but transitory reticulocyte response with no change in the final blood picture. This was interpreted by them as indicative of "a deficiency of the anti-anemic (intrinsic) factor in subacute combined sclerosis despite the presence of a normal blood picture." The fourth observation is that of Reimann and Weil (32). These workers modified Castle's method for demonstrating the presence of intrinsic factor by substituting 10 to 20 grams of whole liver for the 200 grams of beef muscle. This enabled them to use smaller quantities of gastric juice and seemed to give results comparable to those obtained with Castle's technique. In the protocols introduced as evidence, Reimann and Weil cite two experiments in which they used the gastric juice of two patients with achylia gastrica and combined cord degeneration, but no further details are given with respect to these two cases. Reticulocyte responses to 11.4 per cent were obtained in the first instance and to 12.6 per cent in the second. There was a corresponding increase in the erythrocyte count and the hemoglobin.

It is apparent that the interrelationships of these various conditions: pernicious anemia, combined cord degeneration, achlorhydria, and the presence or absence of Castle's "intrinsic factor" are not entirely clear at the present time. Consequently, we have thought it worth while to describe a case of combined system disease without anemia and with marked spontaneous improvement under our observation for over two years, and to report in relation thereto our investigations with regard to the "intrinsic factor."

\section{CASE HISTORY}

The patient (Unit Number 41500), a sixty-one year old unmarried school teacher, was admitted to the Albert Merritt Billings Hospital August 23, 1933, complaining of progressive stiffness and weakness in the lower extremities of about fifteen months' duration and of complete inability to walk for five weeks. The diet had been general; attempts to elicit a history of dietary deficiency were unsuccessful. The general physical examination was negative. There was no lemon yellow tint or pallor of the skin and no atrophy of the papillae of the tongue. The past medical history consisted of scarlet fever, pertussis and measles in childhood, a dilatation of the anal sphincter in 1931, and a tonsillectomy in 1932. There was no history in any respect suggestive of venereal disease. The family history contained nothing noteworthy. The neurological examination by Drs. Percival Bailey and P. M. Levin revealed normal cranial nerves; fairly good motor strength and normal tone in the upper extremities; weakness of the lower extremities in all movements, more those of flexion than of extension, with no paralysis and with a moderate increase in the tone of the leg muscles. There was no muscular atrophy. Pain sensibility was acute everywhere with no level changes. Touch was slightly impaired over the lower extremities. Vibratory sense was lost over the lower extremities, pelvis and lower lumbar spine; intact in the upper extremities. Sense of position was defective in the toes and fingers, more in the former than the latter. 
Impaired stereognosis was present in both hands. Twopoint discrimination was slightly impaired in both hands. There was no ataxia or tremor in the finger-to-nose test with the eyes open or closed, but there was marked ataxia of the legs, worse with the eyes closed. The patient was unable to walk unaided and swayed markedly in the Romberg position. The biceps, triceps, radial, patellar and achilles reflexes were present and equal on the two sides; the upper and lower superficial abdominal reflexes were bilaterally absent; the Babinski and Hoffman signs were bilaterally present and positive. There was no deformity or tenderness of the spine. Impression: Posterolateral syndrome, probably due to subacute combined cord degeneration.

A spinal puncture was performed August 24, 1933. The spinal fluid was clear; the initial pressure $140 \mathrm{~mm}$, promptly rising to $210 \mathrm{~mm}$. upon compression of the right jugular vein; promptly falling upon release of the compression, but immediately rising again to $200 \mathrm{~mm}$. upon compression of the left jugular vein; falling at once upon release, but promptly rising to $250 \mathrm{~mm}$. upon compression of both jugular veins. The cell count was 5 lymphocytes per cc.; there was a faint trace of globulin; the Wassermann reaction was negative; the total nitrogen 0.24 gram per liter.

The blood Wassermann and Kahn tests were negative. The erythrocytes were reported as 4.76 million per cc., the hemoglobin was 90 per cent (Sahli), the leukocytes 8,700 per c.mm., and the smear described as normal. Repeated urinalyses were normal; there was no occult blood in the stool when the patient was given a meat-free diet. Roentgenologic examination of the stomach was reported as normal; the colon was large and described as a megalocolon. The frequently repeated histamine tests of gastric secretion invariably revealed a complete achlorhydria. Gastroscopic examination of the stomach by Dr. Rudolf Schindler performed October 29, 1934, and repeated November 8,1934, revealed a complete atrophy of the entire mucous membrane of the stomach.

Course. The patient remained in the hospital under constant observation for almost two years, and has remained in the neighborhood since her discharge from the hospital. During this time there has been very marked symptomatic improvement. With encouragement and training she has learned to walk almost unaided. Periodic neurologic examinations, however, have failed to disclose any significant change. There has certainly been no evidence of progression of the disease process. The blood count has been reported variously by the changing internes, but at no time have the red cells been less than 4.0 million per cc., or the hemoglobin less than 79 per cent (Sahli). Approximately two years after admission, on October 9, 1935, a hematologic investigation by Dr. Ernestine Kandel revealed a perfectly normal blood picture : erythrocytes, 4.46 million per c.mm.; hemoglobin, 84 per cent (Dare); leukocytes, 9,300 per c.mm.; the differential white count: polymorphonuclear cells, 54 per cent; small lymphocytes, 38 per cent; monocytes, 6 per cent; eosinophils, 1 per cent; basophils, 1 per cent; smear, perfectly normal; cell volume 45 ; volume index, 1.08. The Price-Jones curve (May 15, 1935) was perfectly normal, the peak occurring at 7.4 micra, with a normal distribution.

The patient received no specific therapy-no hydrochloric acid, no liver, and no iron, with the exception of 12 cc. of Lederle's liver extract (each 3 cc. containing the active principle derived from 100 grams of liver) intramuscularly within the first ten days after admission and 4.0 grams of ferrous carbonate, given in a twoday period six weeks later in October, 1933. These did not appear to have any immediate effect and were given empirically before a policy of prolonged observation without specific treatment had been decided upon.

The diagnosis is apparently that of subacute combined cord disease with achlorhydria, but with a normal blood picture, although over three years have elapsed since the onset of the disease.

\section{Experimental procedures}

Experiments were designed to test for the presence in the gastric secretion of the anti-anemic "intrinsic factor." Following the method of Castle and his coworkers (20), gastric juice, following histamine stimulation (.0007 gram), was obtained daily from this patient. Samples were collected every ten minutes for one and one-half hours and pooled. The amounts of secretion thus obtained daily varied from fifty to one hundred twenty-five cubic centimeters. Castle was able to obtain an average of only forty cc. of gastric juice daily while studying a similar case. At the end of each collection period, one hundred cc. of 0.5 per cent $\mathrm{HCl}$ was introduced into the stomach by means of the Rehfuss tube and removed in fifteen minutes. The collected secretion and the washing were pooled and then incubated with two hundred grams of finely ground lean beef at a $\mathrm{pH}$ between 2.5 and 3.5 for two hours. The material was run through a fine sieve and neutralized to a $\mathrm{pH}$ of 5.0.

This extract was given daily for ten days to a sixty-two year old female patient, Unit Number 24714, with the classical symptoms and findings of pernicious anemia without cord changes. The result is shown in Figure 1. On the day following the conclusion of the experiment, the experimental subject was given nine cc. of Lederle's liver extract intramuscularly. There was a typical reticulocyte rise to 18 per cent five days later, preceded by an increase in the red blood count which continued to rise after the reticulocytosis disappeared. We interpret this as a negative response in so far as Castle's extract is concerned, 


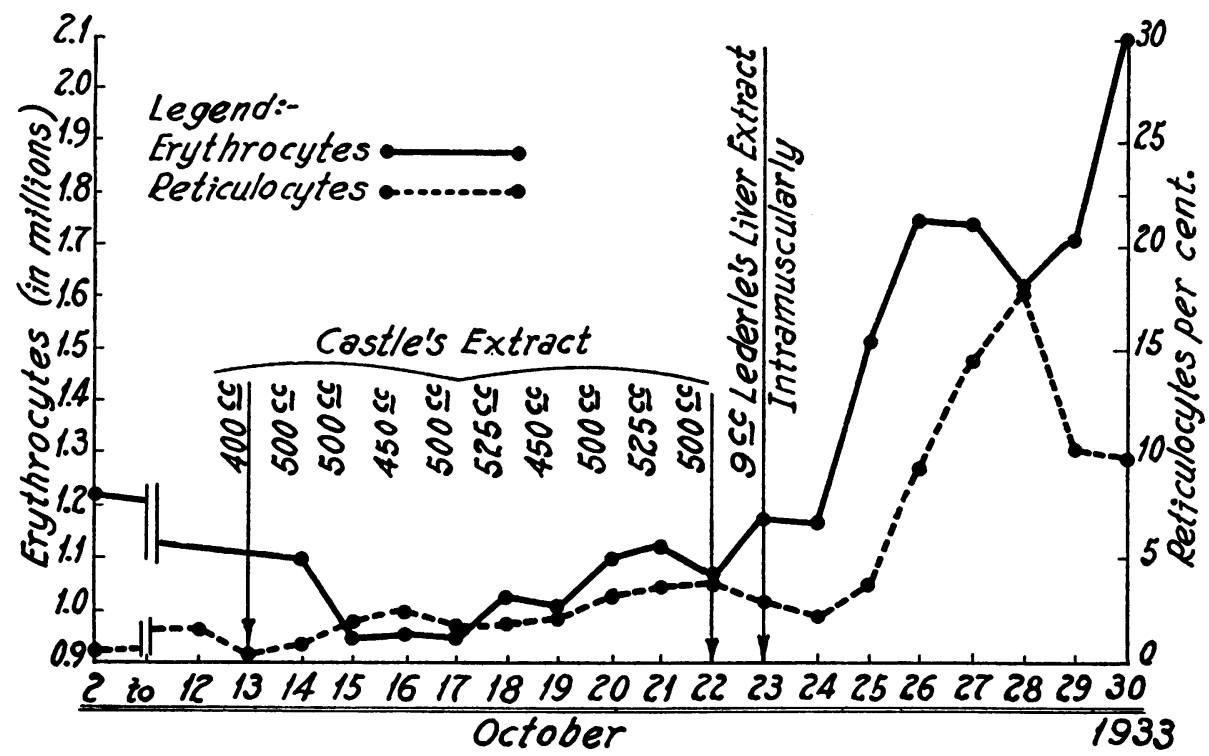

Fig. 1. Negative Response with Extract of Patient's Gastric Juice and Beef.

UNIT NUMBER 24714.

because the reticulocyte count did not exceed 4 per cent until the third day after the intramuscular injection of liver extract, and the erythrocytes did not rise appreciably until the third day after the conclusion of the experiment, the second day after the injection of the liver extract. According to the usual standards, this should be considered a negative experiment, but the early rise in the red blood count after the injection of liver extract and slightly prior to the reticulocytosis suggests that Castle's extract did contain very small amounts of hematopoietic material, and hence presumably very small amounts of intrinsic factor.

Two months later an opportunity arose to repeat the experiment. The test subject was a

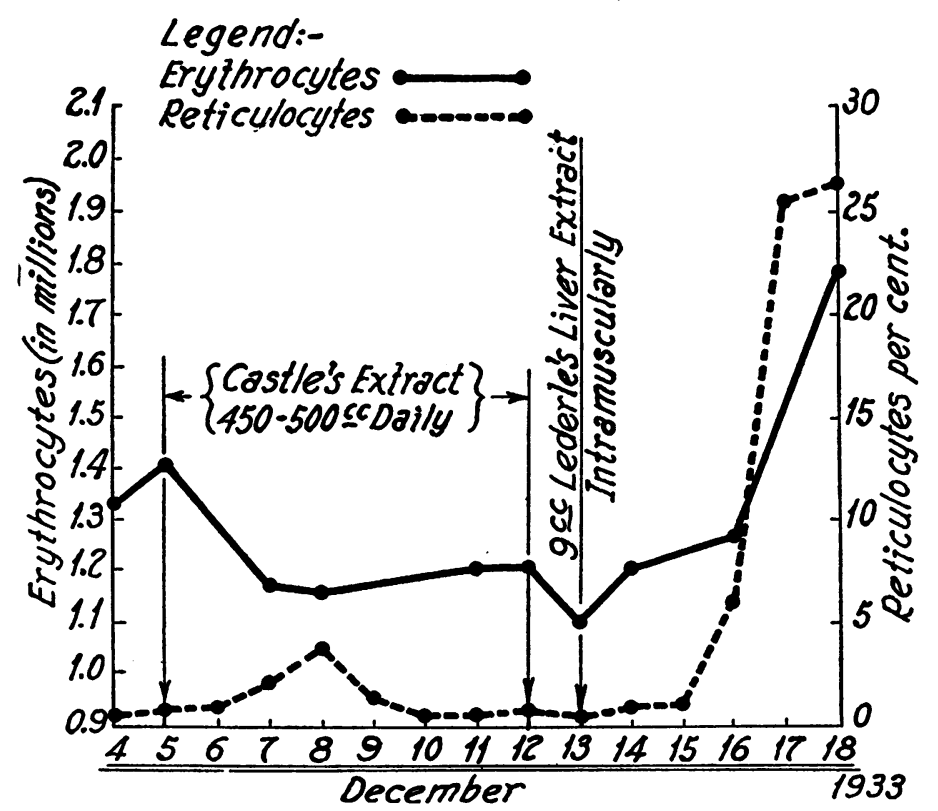

Fig. 2. Negative Response with Extract of Digest of

Patient's Gastric Jutce and Beef. Unit Number 94942. 
male patient, Unit Number 94942, forty-five years of age, with the classical symptoms and findings of pernicious anemia without cord changes. The extract was given for eight days. On the ninth day the patient became so concerned over his lack of improvement that it was necessary to give him parenteral liver extract (Lederle). A typical reticulocyte response appeared three days later, presumably attributable solely to the liver extract, as shown in Figure 2. This experiment is also interpreted as a negative response.

\section{Controls}

Negative experiments of this kind in our opinion may be considered properly as of little value unless controlled in such a fashion as to prove the to Castle's extract when normal human gastric juice and beef are incubated, extracted, and fed to a test subject with pernicious anemia. In this case the test subject was a woman (Unit Number 81754), age sixty-four, who had been under observation and treatment in another institution for five years, during which time the course had been typically that of pernicious anemia with relapses whenever the therapy lapsed as a result of her failure to maintain it. Death subsequently occurred from carcinoma of the stomach-a case falling, in our judgment, into the group described by T. Grier Miller (21) and by Conner and Birkeland (21) and others. The reticulocyte level was rather high, but the rise of both the reticulocytes and the erythrocytes following the

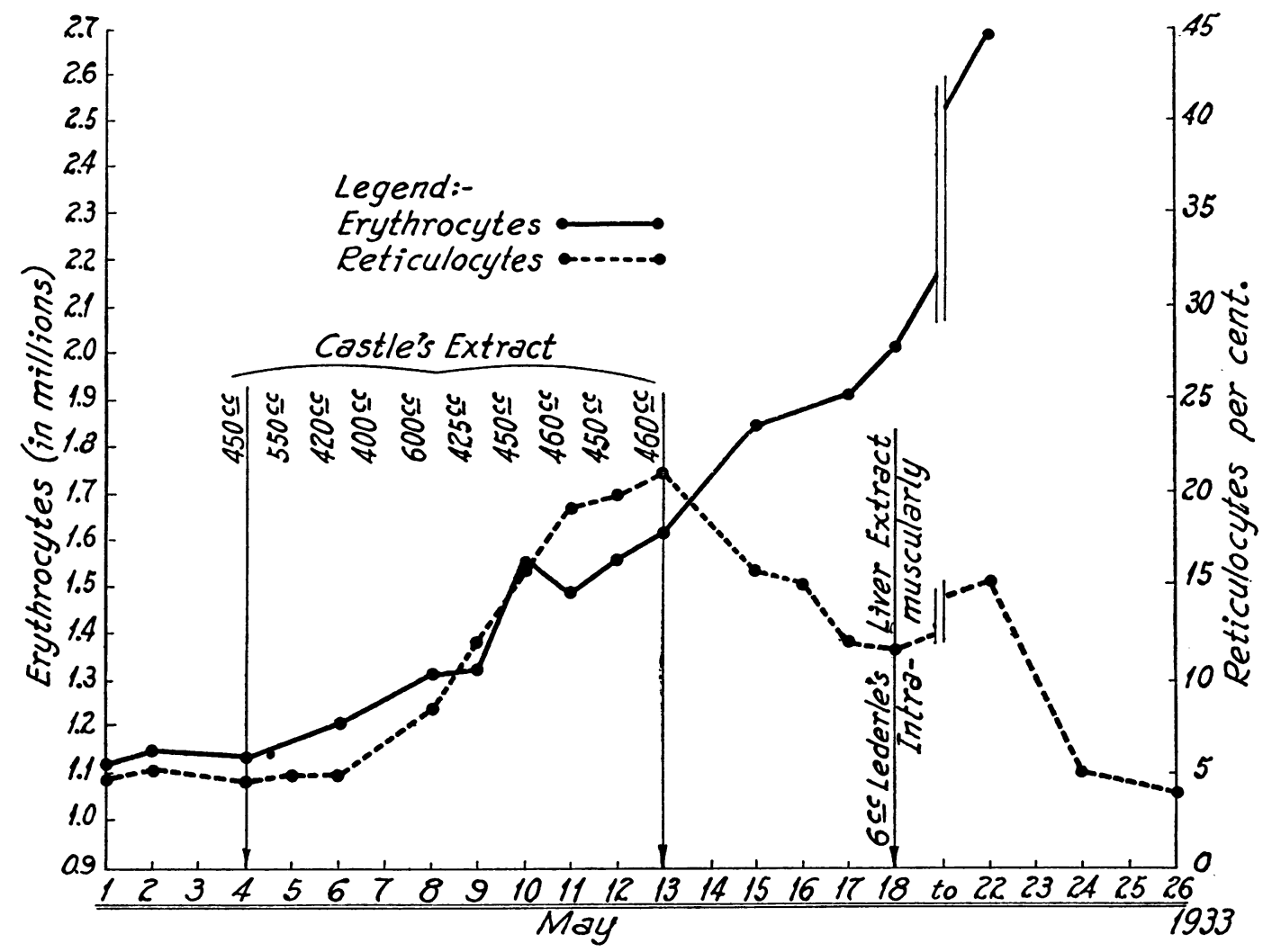

Fig. 3. Control Experiments: Positive Response with Extract of Digest of Normal Human Gastric Juice and Beef. Unit Number 81754.

correctness of the technique employed. For this reason we have felt it necessary to include charts of three control experiments in which exactly the same procedure was carried out. Figure 3 shows the classical reticulocyte and erythrocyte response administration of Castle's extract was very marked and prompt.

Figure 4 shows a somewhat different type of response to a similar extract of normal human gastric juice and meat fed to another patient 


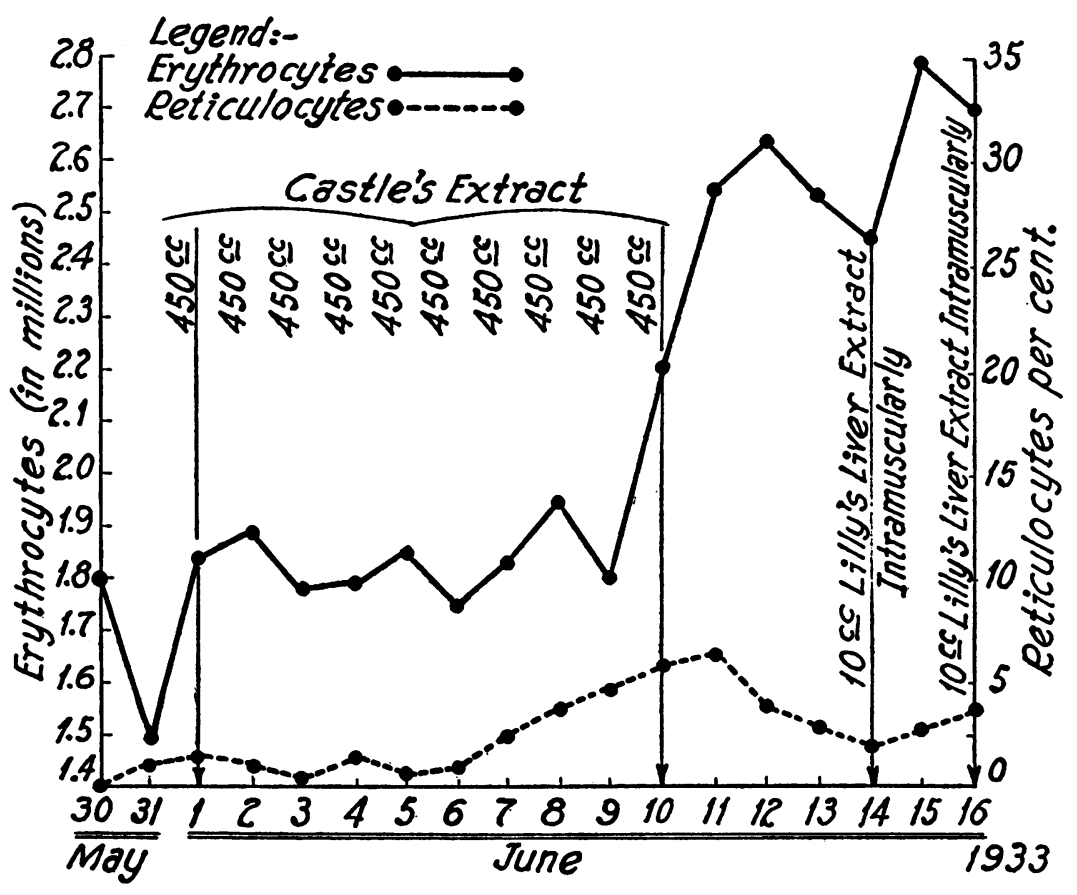

Fig. 4. Control Experiment: Positive Response with Extract of Digest of Normal Human Gastric Juice and Beef. Unit Number 62087.

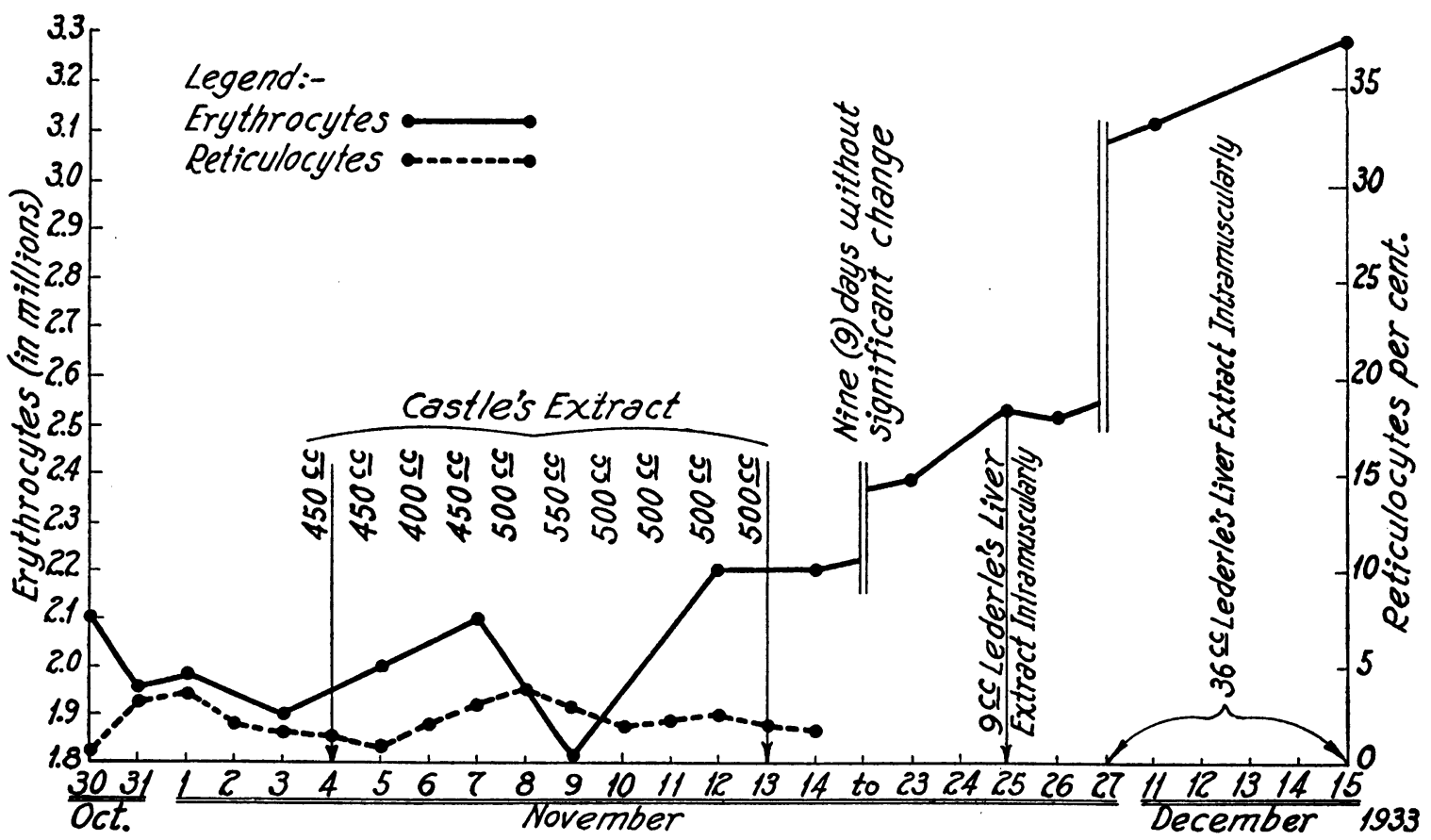

Fig. 5. Control Experiment: Negative Response with Extract of Digest of Beef and Gastric Juice Obtained from a Patient with Pernicious Anemia after Treatment with Liver Extract. Unit Number 92478. 
(Unit Number 62087), a female, age fifty-five, with classical pernicious anemia including combined cord degeneration. In this case the reticulocyte level was very low, less than one per cent, and the response reached a maximum of only 6.2 per cent, but the erythrocyte rise was marked, the count jumping from a level of approximately 1.8 million to 2.6 million two days after the last injection of Castle's extract. These two control experiments illustrate the positive type of response obtained with the extract of normal human gastric juice and beef.

Figure 5 illustrates a control experiment of a negative type. The gastric juice used in this instance was obtained from a patient with pernicious anemia who had been receiving parenteral liver extract therapy. The reticulocyte level remained relatively constant, varying from 0.5 per cent to 3.5 per cent before the period of administration of the extract and also during the period of its administration.

These three control experiments, all of which are in accord with the original observations of Castle, give us confidence in our technique and in attaching real significance to the negative results obtained with the gastric juice of the patient under discussion.

\section{DISCUSSION}

There are two phases of this subject to be considered: the clinical and the experimental. Combined cord degeneration with achlorhydria and without demonstrable abnormality of the blood picture over a period of three years is, in our opinion, sufficiently rare to require reporting. Anemia may appear in time, of course, and thus prove conclusively that the case is merely one of pernicious anemia in which the achlorhydria and the neurologic manifestations have long preceded the alterations in the peripheral blood. This would be in accord with the prevailing clinical opinion. It is noteworthy, however, that in very few of the cases of this type reported in the literature are adequate blood studies described during the period in which anemia is said to have been absent. Such studies are essential for they may disclose a slight but significant anemia or a definite macrocytosis. No such findings were obtained in this patient. In most of the reported cases $(6,12,13,11,15,17,27,28)$ the termina- tion of the disease is not stated, but there are on record two instances of combined cord degeneration without anemia and with a fatal termination. It is possible that with a more critical attitude toward this group, more instances of combined cord degeneration with achlorhydria but without anemia and without " ergotism, pellagra, syphilis, arteriosclerosis and cachectic states " may be encountered and perhaps found to constitute a disease entity entirely unrelated to pernicious anemia.

The spontaneous remission of symptoms in this case is noteworthy. The objective neurologic findings, of course, did not regress materially; but, on the other hand, they showed no evidence of progression. This is as inexplicable at present as is the cause of the disease itself. If iron or liver had been administered enthusiastically, the failure of the disease to progress would undoubtedly have been considered as evidence of the value of the therapy $(17,27)$. In this statement we do not imply that liver therapy is of no value in the combined system disease of pernicious anemia. Our opinion is quite to the contrary although the subject seems to be a controversial one still $(7,22,23,24,25)$. The number of cases of progressive neurological change in patients under adequate liver treatment is certainly small as compared with those seen in the pre-liver era; in fact, they are sufficiently rare to raise the question of the adequacy of the treatment in each instance. In the case under consideration, however, the situation is quite different and in our opinion liver therapy is not indicated at present because the diagnosis of pernicious anemia is, we feel, not established.

The experimental phase of this paper has to do with the interrelationships of the "intrinsic factor" of Castle, achlorhydria, pernicious anemia, and combined cord degeneration. We must confess that there are many aspects of the general problem which are not clear to us in spite of the excellent work of Castle and of other investigators in recent years (supra vide and 26). In this particular case we are quite unable to explain to our own satisfaction the absence of anemia. It is possible to assume that "intrinsic factor" is present in the gastric secretion in subminimal amounts which we failed to detect, but which were adequate to prevent the development of anemia. 
This would be in accord with the findings of Isaacs, Goldhamer, and Sturgis (18). Exact methods for measuring quantitatively the amount of "intrinsic factor" are not available. The amounts of gastric secretion obtained and used by us, however, are comparable to those used by Castle and his coworkers and upon which they based their conclusion with regard to the absence of intrinsic factor in pernicious anemia. The quantities used by us were as great, in fact, as Castle, Heath and Strauss (11) obtained in simple achlorhydria and in sprue, and which they found adequate for the demonstration of "intrinsic factor." Consequently, our failure to obtain a positive response can be compared, we feel, to Castle's failure to obtain a positive response in pernicious anemia. It is possible, as the work of Isaacs, Goldhamer, and Sturgis suggests that the "intrinsic factor" is nevertheless present in minimal amounts. If it be argued that the quantity present in pernicious anemia is not adequate to prevent the appearance of anemia, it is difficult to understand why, in the case under discussion, anemia did not result from a similar decrease in the amount of intrinsic factor. The hypothesis might be advanced that our case contained a greater although not detectable amount of intrinsic factor than is present in pernicious anemia, but there is at present no evidence for this, unless one reasons in a circle and interprets the absence of anemia as evidence of a greater content of intrinsic factor. The fact remains that we failed to demonstrate the presence of intrinsic factor alike in our case of combined cord degeneration without anemia and a case of pernicious anemia under treatment.

It might be argued that anemia did not appear in our case because of the megalocolon and consequent more complete absorption of small amounts of hematopoietic substance. This hypothesis is difficult to prove or disprove. It may be noted, however, that megalocolon is not uncommon in tropical and non-tropical sprue and in celiac disease (30), and that in these conditions it does not prevent the development of a macrocytic anemia which is cured by the administration of liver (31).

The cause of the combined cord degeneration remains obscure. It is tempting to hypothecate, as have others, an "extrinsic factor" different from the anti-anemic extrinsic factor, interacting with the same or another "intrinsic factor." These are interesting speculations, but more facts must be established before a definite theory can be formulated.

\section{SUMMARY}

1. An untreated case of subacute combined cord degeneration of three years' duration, without anemia, with achlorhydria, and with a prolonged spontaneous remission of symptoms is reported.

2. Two experiments designed to demonstrate the presence or absence of the anti-anemic "intrinsic factor" of Castle in the gastric juice of this patient are considered to have given negative results.

3. Control experiments are cited, showing positive results with normal human gastric juice and a negative result in pernicious anemia, all in accord with the observations of Castle and his coworkers.

4. We are unable to offer a completely satisfactory explanation for the absence of anemia, for the presence of the combined cord degeneration, or for the failure of the neurological process to progress during the past two years.

5. Our observations may be interpreted as in accord with either of two views: (a) that combined cord degeneration may be a disease sui generis, or (b) that it is invariably a manifestation of the same basic disorder as that which causes pernicious anemia.

\section{Addendum}

Since the preparation of this manuscript, the work of Greenspon (33) appeared apparently modifying the theory of Castle. It does not materially affect the concept with which this paper is concerned, i.e., the intrinsic factor, but it seemed worth while, nevertheless, to determine the pepsin content of the gastric juice of the patient described. A twenty-cubic centimeter sample was collected during a sixty-minute period following the subcutaneous injection of $0.5 \mathrm{mgm}$. of histamine hydrochloride. Miss Jean Hudson of Dr. Lester Dragstedt's laboratory, using the viscosimeter method (34), was not able to detect any trace of pepsin in the gastric juice. This would seem to substantiate further the validity of our work. 
The patient continues to improve slowly symptomatically. The erythrocyte count March 25, 1936, is 4.21 million, hemoglobin, 82 per cent (Dare), leukocytes, 10,500. The gastroscopic picture as observed the same day remains unchanged, there being a spectacular atrophy of the entire gastric mucous membrane.

The very important work of Dickey and McKinley (35) and of Salus and Weiman (36) was not discovered unfortunately until after this paper had gone to press. The observations reported by these investigators, leading as they do to rather contradictory views, emphasize further the questions we have raised.

\section{BIBLIOGRAPHY}

1. Grinker, Roy R., Neurology. Chas. C. Thomas, Springfield, 1934, p. 865.

2. Cadwalader, Williams B., On the diagnosis of subacute combined sclerosis of the spinal cord associated with severe anemia. J. Nerv. and Ment. Dis., 1916, 44, 424.

3. Hurst, A. F., and Bell, J. R., The pathogenesis of subacute combined degeneration of the spinal cord with special reference to its connection with Addison's (pernicious) anemia, achlorhydria, and intestinal infection. Brain, 1922, 45, 266.

4. Woltmann, H. W., The nervous symptoms in pernicious anemia. An analysis of 150 cases. Am. J. M. Sc., 1919, 157, 400.

5. Weil, Arthur, and Davison, Charles, Changes in the spinal cord in anemia. A clinicomicroscopic study. Arch. Neurol. and Psychiat., 1929, 22, 966.

6. Ungley, C. C., and Suzman, M. M., Subacute combined degeneration of the cord: Symptomatology and effects of liver therapy. Brain, 1929, 52, 271.

7. Sturgis, Cyrus C., Isaacs, Raphael, Goldhamer, S. Milton, Bethell, Frank H., and Farrar, George E., Blood: A review of the recent literature. Arch. Int. Med., 1935, 55, 1001.

8. Bramwell, Byrom, Remarks on a case of subacute combined degeneration of the spinal cord simulating disseminated sclerosis. Brit. Med. J., 1910, $1,1396$.

9. Grinker, Roy R., Pernicious anemia, achylia gastrica, and combined cord degeneration and their relationship. Arch. Int. Med., 1926, 38, 292.

10. Russell, J. S. Risien, Batten, F. E., and Collier, James, Subacute combined degeneration of the spinal cord. Brain, 1900, 23, 39.

11. Castle, William B., Heath, Clark W., and Strauss, Maurice B., Observations on the etiologic relationship of achylia gastrica to pernicious anemia. IV. A biologic assay of the gastric secretion of pa- tients with pernicious anemia having free hydrochloric acid and that of patients without anemia or with hypochromic anemia, having no free hydrochloric acid, and of the rôle of intestinal permeability to hematopoietic substances in pernicious anemia. Am. J. M. Sci., 1931, 182, 741.

12. Allen, I. M., Subacute combined degeneration of spinal cord without anemia. Proc. Roy. Soc. Med., 1928-29, 22, Part I, 177.

13. Vanderhoof, Douglas, The etiologic relation of achylia gastrica to combined sclerosis of the spinal cord. Arch. Int. Med., 1923, 32, 958.

14. Oliver, T. H., and Wilkinson, John F., Critical review -achlorhydria. Quart. J. Med., 1933, 2 (n. s.), 431.

15. Beebe, R. T., and Wintrobe, M. M., Diagnosis of obscure cases of pernicious anemia. Arch. Int. Med., 1933, 51, 630.

16. Greenfield, J. G., and O'Flynn, Elizabeth, Subacute combined degeneration and pernicious anemia. Lancet, 1933, 2, 62.

17. Sargant, Will, Treatment of subacute combined degeneration of the cord by massive iron dosage. Lancet, 1932, 1, 230.

Sargant, Will, and Langmead, F. S., On the treatment of nervous disorders accompanying anemia by intensive iron therapy. Lancet, 1932, 2, 1322.

Sargant, William, and Harris, Wilfred, A case of combined sclerosis without anemia treated by intensive iron therapy. Brit. Med. J., 1933, 1, 1100.

18. Isaacs, Raphael, Goldhamer, S. Milton, and Sturgis, Cyrus C., Rôle of decreased amount of gastric secretion in production of pernicious anemia. Proc. Soc. Exper. Biol. and Med., 1934, 31, 706.

Inadequate amount of gastric secretion as a factor in the production of pernicious anemia. J. Clin. Invest. (Proc.), 1934, 13, 710.

19. Barnett, C. W., The significance of the gastric secretions in pernicious anemia. Am. J. M. Sc., 1931, 182, 170; 1932, 184, 24.

20. Castle, William B., The etiology of pernicious and related macrocytic anemias. Science, 1935, 82, 159.

Castle, W. B., and Locke, E. A., Observations on the etiological relationship of achylia gastrica to pernicious anemia. J. Clin. Invest. (Proc.), 1928, 6, 2.

Castle, W. B., Observations on the etiologic relationship of achylia gastrica to pernicious anemia. I. The effect of the administration to patients with pernicious anemia of the contents of the normal human stomach recovered after the ingestion of beef muscle. Am. J. M. Sc., 1929, 178, 748.

Castle, W. B., and Townsend, W. C. Idem. II. The effect of the administration to patients with pernicious anemia of beef muscle after incubation with normal human gastric juice. Am. J. M. Sc., 1929, 178, 764.

Castle, W. B., Townsend, W. C., and Heath, C. W., Idem. III. The nature of the reaction between nor- 
mal human gastric juice and beef muscle leading to clinical improvement and increased blood formation similar to the effect of liver feeding. Am. J. M. Sc., 1930, 180, 305.

21. Miller, T. Grier, Addisonian anemia and carcinoma of the stomach in the same individual. Report of three cases: Chronic gastritis as a probable basis for both diseases. Internat. Clin. 1935, 1, 167.

Conner, H. Milton, and Birkeland, Ivar W., Coexistence of pernicious anemia and lesions of the gastro-intestinal tract. I. Carcinoma of the stomach, consideration of twenty cases: Eleven reported. Ann. Int. Med., 1933, 7, 89.

22. Garvey, P. H., Levin, P. M., and Guller, E. I., The effect of liver therapy on the neurologic aspects of pernicious anemia. Ann. Int. Med., 1933, 6, 1441.

23. Grinker, Roy R., and Kandel, Ernestine, Pernicious anemia. Results of treatment of the neurologic complications. Arch. Int. Med. 1934, 54, 851.

24. Haden, Russell L., The complete treatment of pernicious anemia. Am. J. Digest. Dis. and Nutrition, 1934, 1, 628.

25. Strauss, M. B., Solomon, Philip, Schneider, Antoine J., and Patek, Arthur J., Jr., Subacute combined degeneration of the spinal cord in pernicious anemia. The complete arrest of the lesion with parenteral liver therapy. J. A. M. A., 1935, 104, 1587.

26. Gildea, Margaret Crane-Lillie, Castle, W. B., Gildea, Edwin F., and Cobb, Stanley, Neuropathology of experimental vitamin deficiency. A report of 4 series of dogs maintained on diets deficient in the B vitamins. Am. J. Path., 1935, 11, 669.

27. Sanford, Conley H., Pernicious anemia with normal blood picture. Ann. Int. Med., 1935, 9, 189.

28. Briggs, John F., and Oerting, Harry, The gastric anti-anemic factor in subacute combined sclerosis. Proc. Cent. Soc. for Clin. Research, Nov. 1, 1935, p. 23. (Unpublished.)
29. Hartfall, S. J., and Witts, L. J., The intrinsic factor of Castle in simple achlorhydric anemia. Guy's Hosp. Rep., 1933, 83, 24.

30. Holmes, Wm. H., and Starr, Paul, A nutritional disturbance in adults resembling celiac disease and sprue. J. A. M. A., 1929, 92, 975.

Thaysen, Th. E. Hess, Non Tropical Sprue. Oxford University Press, London, 1932.

Thaysen, Th. E. Hesse, Ten cases of idiopathic steatorrhoea. Quart. J. Med., 1935, 4, 359.

31. Rhoads, C. P., and Miller, D. K., Intensive liver extract therapy of sprue. J. A. M. A., 1934, 103, 387.

Castle, W. B., Rhoads, C. P., Lawson, H. A., and Payne, G. C., Etiology and treatment of sprue. Observations on patients in Puerto Rico and subsequent experiments on animals. Arch. Int. Med., $1935,56,627$.

32. Reimann, F., and Weil, R., Uber den Nachweis des Castleschen Fermentes. III. Untersuchungen zur Leberwirkung bei der Anaemia Perniciosa. Ztschr. f. klin. Med., 1934, 126, 568.

33. Greenspon, E. A., The nature of the antipernicious anemia principle in stomach. I. Method to improve stomach preparations. J. A. M. A., 1936, 106, 266.

34. Waksman, S. A., and Davison, W. C., Enzymes. The Williams and Wilkins Co., Baltimore, 1926, p. 211.

35. Dickey, L. B., and McKinley, J. C., Subacute combined degeneration of the spinal cord without pernicious anemia: Report of two cases with autopsy findings. Lancet, 1925, 45, 331.

36. Salus, F., and Reimann, F., Das Castlesche Ferment und Die Funikuläre Spinalerkrankung. Ein Beitrag zur Pathogenese des nervösen Krankheitssyndroms. (VI. Untersuchungen zur Leberwirkung bei der Anaemia perniciosa.) Klin. Wchnschr., 1934, 13, 986. 